Erratum

\title{
Erratum: Ingelfinger, J.R.; et al. Averting the Legacy of Kidney Disease-Focus on Childhood. Children 2016, 3, 4
}

\section{Children Editorial Office}

MDPI AG, Klybeckstrasse 64, CH-4057 Basel, Switzerland; children@mdpi.com; Tel. +41-61-683-77-34;

Fax: +41-61-302-89-18

Received: 13 April 2016; Accepted: 13 April 2016; Published: 18 April 2016

The Children Editorial Office wishes to notify its readers of a correction in [1]. In proofing, the abbreviation $\mathrm{HN}$ was changed to hypertension. HN stands for hereditary nephropathy and should have been defined as such when a legend was added in proofing. However, due to the change in the abbreviation to hypertension, hypertension was erroneously inserted in the legend.

The Table 2 should read:

Table 2. Etiology of chronic kidney disease in children *.

\begin{tabular}{cccc}
\hline CKD Etiology & Percentage (Range) & ESRD Etiology & Percentage (Range) \\
\hline CAKUT & $48 \%-59 \%$ & CAKUT & $34 \%-43 \%$ \\
GN & $5 \%-14 \%$ & GN & $15 \%-29 \%$ \\
HN & $10 \%-19 \%$ & HN & $12 \%-22 \%$ \\
HUS & $2 \%-6 \%$ & HUS & $2 \%-6 \%$ \\
Cystic & $5 \%-9 \%$ & Cystic & $6 \%-12 \%$ \\
Ischemic & $2 \%-4 \%$ & Ischemic & $2 \%$ \\
\hline
\end{tabular}

Rare causes include congenital NS, metabolic diseases, cystinosis/miscellaneous causes depend on how such entities are classified. CAKUT: Congenital anomalies of the kidney and urinary tract; GN: Glomerulonephritis; HN: Hereditary nephropathy; HUS: Hemolytic uremic syndrome. * from Harambat et al. CKD data are from NAPRTCS, the Italian Registry and the Belgian Registry. ESRD: end-stage renal disease; ESRD data are from ANZDATA, ESPN/ERA-EDTA, UK Renal Registry, and the Japanese Registry.

The manuscript will be updated and the original will remain available on the article webpage. The authors would like to apologize for any inconvenience caused.

\section{References}

1. Ingelfinger, J.R.; Kalantar-Zadeh, K.; Schaefer, F. Averting the legacy of kidney disease-Focus on childhood. Children 2016, 3, 4. [CrossRef]

(C) 2016 by the author; licensee MDPI, Basel, Switzerland. This article is an open access article distributed under the terms and conditions of the Creative Commons Attribution (CC-BY) license (http://creativecommons.org/licenses/by/4.0/). 